\title{
PENGARUH DUKUNGAN SPIRITUAL TERHADAP KUALITAS HIDUP PENDERITA KANKER PAYUDARA PASCA KEMOTERAPI
}

\author{
Yusniarita, Rini Patroni, Ratna Ningsih \\ Politeknik Kesehatan Kementerian Kesehatan Bengkulu, Jurusan Kebidanan, \\ Jalan Indragiri Nomor 03 Padang Harapan Kota Bengkulu
}

\begin{abstract}
jmkbengkulu@gmail.com
Abstract : The Rejang Lebong district prevalence of breast cancer in women of reproductive age or premenopausal compare with women who had menopause also affects of treatment such as chemotherapy and lack of family support in the from of spiritual support could influence quality of the life of patients. The purpose of this study to determine the effect of spiritual support to the quality of life of breast cancer patients post chemotherapy at Rejang Lebong district. Metode Quasi Experiment One Group Pre dan Post Test. The was population 33 and sampel was 12 respondents. There are differnences in the quality of research results to support the spiritual life of breast cancer patients after chemotherapy in Rejang lebong district 2014. This discusstions are expected to patients in order to inprove the quality of life and spiritual breast cancer patients for example thorough spiritual activities such as recitation and for health workers in order to conduof health education about breast cancer.
\end{abstract}

Key words : Supports spiritual, life quality

\begin{abstract}
Abstrak : Di Kabupaten Rejang Lebong angka prevalensi kanker payudara pada wanita berusia reproduksi atau belum mengalami menopause dibandingkan dengan wanita yang telah menopause juga berpengaruh terhadap kualitas hidup dan pengalaman spiritual yang dialami oleh penderita masih relatif tinggi. Tingginya kejadian kanker payudara beserta dampak efek samping pengobatan berupa kemoterapi dan rendahnya dukungan keluarga berupa dukungan spiritual yang dapat mempengaruhi kualitas hidup penderita. Tujuan penelitian untuk mengetahui pengaruh dukungan spiritual terhadap kualitas hidup penderita kanker payudara pasca kemoterapi di Kabupaten Rejang Lebong. Metode penelitian Quasi Experiment One Group Pre dan Post Test Jumlah polpulasi 33 responden dan sampel adalah 12 responden. Hasil penelitian Ada perbedaan kualitas hidup terhadap dukungan spiritual penderita kanker payudara pasca kemoterapi di Kabupaten Rejang Lebong tahun 2014. Diharapkan kepada penderita agar dapat meningkatkan kualitas hidup dan spiritual penderita kanker payudara misalnya melalui aktivitas kerohanian seperti pengajian dan tenaga kesehatan agar mengadakan kegiatan penyuluhan kesehatan mengenai penyakit kanker payudara
\end{abstract}

Kata Kunci :Dukungan spiritual, kualitas hidup

Kanker dapat menyerang semua lapisan masyarakat tanpa mengenal status sosial, umur,dan jenis kelamin. Anak-anak, remaja, dan orang dewasa tak luput dari serangan kanker. Begitu pula dengan pria dan wanita dapat teserang penyakit yang paling banyak ditakuti ini. Namun, dari data yang ada kaum wanita paling banyak terkena kanker. Penyakit ini sebenamya timbul akibat kondisi fisik yang tidak normal Berta pola makan dan pola hidup yang tidak sehat, meskipun kanker diketahui bisa diturunkan oleh orang tua kepada anaknya. Kaum wanita cukup rentan terhadap serangan kanker, terutama organ reproduksi seperti payudara, rahim, indung telur dan vagina. Bagi wanita, penyakit, ini menjadi momok yang menakutkan. Kanker termasuk penyakit yang tidakmenular. Penyakit ini timbul akibat kondisi fisik yang tidak normal dan pola hidup yang tidak sehat. Meskipun demikian, penyakit ini bisa diturunkan oleh orang tua kepada anaknya. Risiko terkena kanker sangat besar jika salah satu anggota keluarga terkena keluarga (Lina, 2009).

Kanker payudara merupakan kanker terbanyak pada wanita diseluruh dunia dan Indonesia masih belum diketahui secara pasti karena belum ada registrasi kanker berbasis 
populasi yang dilaksanakan. Data IARC tahun 2002, perkiraan kejadian merupakan penyebab kematian kedua dari seluruh kematian yang disebabkan oleh kanker. Menurut American Cancer Society, sekitar 1,3 juta wanita didiagnosa kanker payudara di seluruh dunia. Asia mempunyai angka kejadian kenker payudara lebih tinggi dibandingkan Negara Eropa dan Amerika.Insisden kanker di kanker payudara di Indonesia 26 per 100.000 perempuan (Depkes RI., 2008).

Insidensi kanker payudara dibanyak Negara meningkat $1-2 \%$ setiap tahunnnya. Kurva insidensi berdasarkan usia bergerak naik terus dari usia 30 tahun. Kanker payudara jarang ditemukan pada wanita dibawah usia 20 tahun. Meskipun ada perbaikan diagnosis dan terapi, bagi penderita kanker payudara, tetapi kematian karena penyakit ini terus meningkat (Narti \& Budiyani, 2009). Intervensi yang dilakukan kepada penderita kanker payudara dapat dilakukan dengan cara mengeliminasi kankernya yaitu dengan kemoterapi, radiasi, dan operasi. Keputusan untuk memberikan terapi kepada pasen tidak hanya mempertimbangkan data kekambuhan, survival, efek toksisitas akut yang akan dialami pasien, namun juga mempertimbangkan implikasinya terhadap kualitas hidup pasien (Ganz, et all., 2002).

Ditinjau dari psikologis penderita kanker payudara sangat membutuhkan dukungan spiritual dan dukungan dari keluarga untuk mengatasi dampak stress yang timbul dari pengobatan, operasi, putus asa dengan penyakitnya, dan komplikasi lain yang akan terjadi dikemudian hari. Banyak cara yang dapat dilakukan untuk mengatasi terjadinya stress dan depresi pada penderita, misalnya berbagi pengalaman dengan sesama penderita, meningkatkan mekanisme koping, healing therapy, dan spiritual therapy.

Spiritual merupakan bagian dari keseluruhan diri manusia. Pentingnya dimensi spiritual dalam pelayanan kesehatan dapat dilihat dari batasan organisasi kesehatan dunia yang menyatakan bahwa aspek spiritual merupakan salah satu unsur dari pengertian kesehatan seutuhnya. WHO memberikan batasan sehat dari 3 aspek yaitu sehat fisik, sehat mental dan sehat sosial. Pengertian ini berubah pada tahun 1984, batasan sehat tersebut sudah ditambah dengan aspek agama (spiritual)yang oleh American Phsychiatric Association (APA) dikenal dengan rumusan bio-psiko-sosio-spiritual (Hawari.D., 2002).

Selama ini dimensi spiritual sering dilupakan dalam praltek pelayanan kesehatan. Menurut Hawari (2002) ada dikotomis hubungan antara kesehatan dengan spiritual dalam pelaksanaan praktek kesehatan di Indonesia, padahal mayoritas penduduk Indonesia adalah muslim. Apa yang seharusnya dilakukan oleh seorang muslim, baik itu petugas kesehatan maupun sebagai pasien adalah memiliki akidah yang kuat, ibadah yang tekun dan akhlak yang terpuji. Semuanya harus bergerak seimbang dan berdampingan dalam kehidupan sehari-hari. Salah satu faktor penyebab terjadinya ketidakseimbangan dimensi spiritual dengan praktek kesehatan adalah tata fikir yang keliru dari tenaga medis. Selama ini banyak tenaga medis yang menganggap bahwa menerapkan dimensi spiritual bukan tanggungjawabnya. Dalam penelitian Vance (2001) terhadap 173 perawat di Midwestern Community Nursing menemukan hanya $34,6 \%$ yang mendukung perawatan spiritual.

Hal senada diungkapkan Makhija (2002) bahwa pelayanan keperawatan masih berfokus pada pemenuhan kebutuhan fisik saja, dan pemenuhan aspek spiritual umumnya belum diperhatikan dengan baik. Hallstead and Hull (2001) melakukan penelitian pada penderita kanker lymphoma, payudara, ovarium menyatakan bahwa penderita kanker dapat melawan keadaan sakitnya dengan mencoba meningkatkan penerimaan dan keyakinan bahwa hidup dengan kanker adalah bagian hidup yang harus dijalaninya tetapi disisi lain mereka kerasakan hidupnya menjadi tidak pasti dan kesembuhannnya bukan dari Tuhan.

Sebaliknya Sinclain et al.,(2006) menyatakan bahwa pemenuhan kebutuhan spiritual merupakan bentuk pelayanan keperawatan bagi penderita penyakit terminal. Narayanasami (2007) mengungkapkan bahwa spiritual dapat menjadi mekanisme koping dan faktor yang berkontribusi penting terhadap 
prose pemulihan pasien. Bussing, et al.,(2008) pasien kanker memiliki sandaran religius yang kuat akan mengantarkan mereka pada prognosis yang lebih baik dari yang diperkirakan. Dapat disimpulkan bahwa aspek spiritual merupakan bagian dari perawatan paliatif. Spiritualitas yang baik membuat seseorang menjadi lebih tenang, konsentrasi meningkat, dan berfikir positif, senantiasa mengkreasikan perasaan hidup sejahtera. Perawatan spiritual sangat mirip dengan konseling dan psikoterapi bertujuan untuk merawat spirit seseorang agar pulih kembali.

Operasi pengangkatan payudara meninggalkan kesan bagian tubuh menjadi tidak sempurna dan meninggalkan kesan buruk, sedangkan kemoterapimemiliki efek samping kemoterapi jangka pendek seperti mual, muntah, lemas, rambut rontok, mudah mengalami infeksi, ada juga pasien yang mengalami efek jangka panjang dari kemoterapi infertilitas, osteoporosis, penurunan fungsi mental, gangguan konsentrasi dan memori sampai depresi. Efek samping ini akan menghilang setelah selesainya kemoterapi. Semua efek samping tersebut dapat berpengaruh pada kualitas hidup pasien (Cancer Reference Information, 2007).

Pengobatan kanker pada stadium lanjut sangat sulit dan hasilnya kurang memuaskan (Manuaba, 2008). Pada stadium lanjut pasien tidak hanya mengalami berbagai masalah fisik, tetapi juga masalah psikologis, spiritual yang mempengaruhi kualitas hidup pasien. Penelitian Hendarnejad et al (2009) mengenai kualitas hidup penderita pasca kemoterapi pada 200 pasien kanker didapatkan 22 (11\%) pasien kualitas hidupnya baik,132 (66\%) kualitas hidupnya sedang, dan 46 (23\%) kualitas hidupnya buruk, oleh seab itu kebutuhan pasien bukan hanya pada pemenuhan pengobatan gejala fisik saja, namun juga pentingnya dukungan terhadap kebutuhan psikologis, sosial, dan spiritual dengan pendekatan interdisiplin (Menkes RI., 2007)

Seseorang yang telah divonis mengidap kanker payudara mengalami perubahan dalam hidupnya. Menurut Karyono, Dewi dan Lela (2008) menyatakan bahwa penyakit kanker berhubungan dengan kualitas hidup yang terdiri dari beberapa dimensi yaitu kesejahteraaan fisik, psikologis, fingsional dan social. Penderita kanker payudara mudah mengalami stress dan tekanan emosional yang belebihan dan dapat memicu kondisi distress setelah melakukan diagnosis dan treatment. Sekitar $45 \%$ wanita yang didiagnosis mengalami gejala kecemasan ringan sampai berat, $28 \%$ wanita mengalami depresi ringan sampai parah. Penderita kanker payudara umumnya mengalami gejala kecemasan dan depresi yang menganggu fungsi fisik, kualitas kesehatan dan kualitas seksualnya (Kayser, Fieldman et al., 2010).

Data dari RSUP Dr. Sardjito jumlah penderita baru kanker payudara tahun 2008 sebanyak 363 penderita. Menurut beberapa dokter di instalasi Kanker Tulip Terpadu menyatakan bahwa penilaian kualitas hidup bagi penderita kanker penting untuk mengevaluasi kualitas hidup penderita dan mengevaluasi hasil pengobatan. Di Kabupaten Rejang Lebong, berdasarkan survei di Rumah Sakit Umum Daerah Curup dilaporkan bahwa pada tahun 2007 terdapat 32 kasus tumor payudara, 6 kasus $(18,75 \%)$ terjadi pada usia 15-24 tahun, 19 kasus $(59,37 \%)$ terjadi pada usia 25-44 tahun, dan 7 kasus $(21,87 \%)$ terjadi pada usia 45-59 tahun, 3 orang diantaranya meninggal . Sedangkan pada tahun 2012 sampai dengan bulan Desember, terdapat 8 kasus tumor payudara dimana 3 kasus $(37,5 \%)$ diantaranya terjadi pada usia 15-24 tahun, 2 kasus (25\%) terjadi pada usia 25-44 tahun dan 3 kasus (37,5\%) terjadi pada usia 45-59 tahun,dan empat orang diantaranya meninggal karena kanker payudara. (RSUD Curup,2012). Tingginya angka prevalensi kanker payudara pada wanita berusia reproduksi atau belum mengalami menopause dibandingkan dengan wanita yang telah menopause juga berpengaruh terhadap qualitas hidup dan pengalaman spiritual yang dialami oleh penderita. Tujuan penelitian untuk mengetahui pengaruh dukungan spiritual terhadap kualitas hidup penderita kanker payudara pasca kemoterapi di Kabupaten Rejang Lebong 


\section{BAHAN DAN CARA KERJA}

Desain Penelitian Quasi Experiment One Group Pre dan Post Test. Analisis data univariat Setelah data terkumpul dalam bentuk tabel distribusi frekuensi masing-masing variabel penelitian dengan menggunakan ukuran proporsi.

Populasi dalam penelitian ini adalah seluruh penderita kanker payudara sejumlah 33 orang. Sampel adalah sebagian yang diambil dari keseluruhan objek yang diteliti dan diangggap mewakili seluruh populasi. Teknik pengambilan sampel dalam penelitian ini adalah dengan cara non probability sampling yaitu secara purposive sampling.

Instrumen kualitas hidup menopause menurut WHOQOL-BREF. Analisis menggunakan uji $\mathrm{t}$ dependent bila data terdistribusi normal jika data berdistribusi tidak normal maka menggunakan uji wilcoxon.

\section{HASIL}

Distribusi frekuensi karakteristik penderita kanker payudara pada tabel 1 menunjukan bahwa umur penderita kanker payudara pasca kemoterapi sebagian $(49,50)$ dan sebagian penderita berpendidikan SMA.

Tabel 2 menunjukkan bahwa sebagian besar pre intervensi penderita kanker payudara pasca kemoterapi selama 4 minggu $(58,3 \%)$ memiliki dukungan spiritual yang tidak baik. Menunjukkan bahwa hampir seluruh post intervensi penderita kanker payudara pascakemo terapi selama 4 minggu $(83,3 \%)$ memiliki dukungan spiritual yang baik.

Tabel 1. Distribusi Frekuensi Karakteristik

\begin{tabular}{lcc}
\hline Karakteristik Responden & Frekuensi & Presentase \\
\hline Umur & & \\
37 tahun & 1 & $8,3 \%$ \\
43 tahun & 1 & $8,3 \%$ \\
46 tahun & 2 & $16,7 \%$ \\
49 tahun & 2 & $16,7 \%$ \\
50 tahun & 2 & $16,7 \%$ \\
53 tahun & 2 & $16,7 \%$ \\
61 tahun & 1 & $8,3 \%$ \\
Pendidikan & 1 & $8,3 \%$ \\
SD & & \\
SMP & 3 & $25,0 \%$ \\
SMA & 1 & $8,3 \%$ \\
D III & 5 & $41,7 \%$ \\
SI & 1 & $8,3 \%$ \\
\hline
\end{tabular}

Tabel 2 Distribusi Frekuensi Dukungan spiritual penderita Kanker

\begin{tabular}{ccc}
\hline Dukungan spiritual & Frekuensi & Presentase \\
\hline Pre Intervensi & & \\
\hline Baik & 5 & $41,7 \%$ \\
Tidak Baik & 7 & $58,3 \%$ \\
\hline \multirow{2}{*}{ Post Intervensi } & 10 & $83,3 \%$ \\
& 2 & $16,7 \%$ \\
\hline
\end{tabular}

Tabel 3. Distribusi Frekuensi Pre ntervensi Kualitas Hidup Penderita Kanker

\begin{tabular}{lcc}
\hline \multicolumn{1}{c}{ Kualitas Hidup } & Frekuensi & Presentase \\
\hline Kesehatan Fisik & 5 & $41,7 \%$ \\
Baik & 7 & $58,0 \%$ \\
Tidak Baik & & \\
Kesehatan Mental & 3 & $25,0 \%$ \\
Baik & 9 & $75,0 \%$ \\
Tidak Baik & & \\
Dukungan Sosial & 6 & $50,0 \%$ \\
Baik & 6 & $50,0 \%$ \\
Tidak Baik & & \\
Lingkungan & 5 & $41,7 \%$ \\
Baik & 7 & $58,3 \%$ \\
Tidak Baik & & \\
\hline
\end{tabular}

Tabel 3 menunjukkan bahwa sebagian besar pre intervensi penderita kanker payudara pasca kemoterapi $(58,0 \%)$ memiliki kualitas hidup pada kesehatan fisik yang tidak baik, sebagian besar $(75,0 \%)$ memiliki kualitas hidup pada kesehatan mental yang tidak baik, sebagian $(50,0)$ memiliki kualitas hidup pada dukungan sosial yang tidak baik dan $(58,0)$ sebagian penderita memiliki kualitas hidup pada lingkungan yang tidak baik.

Tabel 4. Distribusi Frekuensi Post Intervensi Kualitas Hidup Penderita Kanker

\begin{tabular}{|c|c|c|}
\hline Kualitas Hidup & Frekuensi & Presentase \\
\hline \multicolumn{3}{|l|}{ Kesehatan Fisik } \\
\hline Baik & 6 & $50,0 \%$ \\
\hline Tidak Baik & 6 & $50,0 \%$ \\
\hline \multicolumn{3}{|l|}{ Kesehatan Mental } \\
\hline Baik & 7 & $58,0 \%$ \\
\hline Tidak Baik & 5 & $41,7 \%$ \\
\hline \multicolumn{3}{|l|}{ Dukungan Sosial } \\
\hline Baik & 7 & $58,8 \%$ \\
\hline Tidak Baik & 5 & $41,7 \%$ \\
\hline \multicolumn{3}{|l|}{ Lingkungan } \\
\hline Baik & 7 & $58,8 \%$ \\
\hline Tidak Baik & 5 & $41,7 \%$ \\
\hline \multicolumn{3}{|c|}{$\begin{array}{l}\text { Menunjukkan bahwa sebagian post } \\
\text { intervensi penderita kanker payudara pasca } \\
\text { kemoterapi }(50,0 \%) \text { memiliki kualitas hidup } \\
\text { pada kesehatan fisik yang baik, sebagian } \\
(58,0 \%) \text { memiliki kualitas hidup pada } \\
\text { kesehatan mental yang baik, sebagian }(58,3)\end{array}$} \\
\hline
\end{tabular}


memiliki kualitas hidup pada dukungan sosial yang baik dan $(58,0)$ sebagian penderita memiliki kualitas hidup pada lingkungan yang baik.

Tabel 5. Rerata kualitas hidup sebelum dan sesudah dukungan spiritual pada penderita kanker payudara pasca kemoterapi

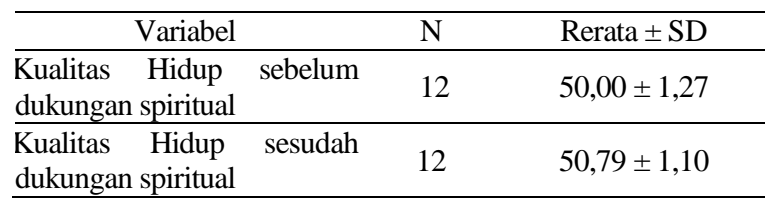

Diketahui bahwa Rerata kualitas hidup sebelum dilakukan dukungan spiritual lebih rendah dibandingkan dengan Rerata kualitas hidup sesudah dilakukan dukungan spiritual. Rerata kualitas hidup sebelum dilakukan dukungan spiritual sebesar $50,00 \pm 1,27$ sedangkan Rerata kualitas hidup sesudah dilakukan dukungan spiritual sebesar 50,79 $\pm 1,10$.

Tabel 6 Diketahui hasil uji $t$-dependent didapatkan nilai $p=0,008(p<0,05)$ dengan demikian disimpulkan terdapat perbedaan Rerata kualitas hidup yang bermakna sebelum dan sesudah dilakukan dukungan spiritual. Nilai IK 95\% 0,24-1,33

Tabel 6. Hasil uji t-dependent kualitas hidup sebelum dan sesudah Dilakukan dukungan spiritual pada penderita kanker Payudara pasca kemoterapi

\begin{tabular}{|c|c|c|c|c|}
\hline Variabel & $\mathbf{N}$ & Rerata \pm SD & $\begin{array}{c}\text { Perbedaan } \\
\text { Rerata } \pm \text { SD }\end{array}$ & IK 95\% $P$ \\
\hline $\begin{array}{l}\text { Kualitas } \\
\text { Hidup } \\
\text { sebelum } \\
\text { dukungan } \\
\text { spiritual }\end{array}$ & 12 & $50,00 \pm 1,27$ & $0,790 \pm 0,856$ & 0,24-1,33 0,008 \\
\hline $\begin{array}{l}\text { Kualitas } \\
\text { Hidup } \\
\text { sesudah } \\
\text { dukungan } \\
\text { spiritual }\end{array}$ & 12 & $50,79 \pm 1,10$ & & \\
\hline
\end{tabular}

\section{PEMBAHASAN}

\section{Karakteristik penderita kanker payudara}

Hasil penelitian ini didapat bahwa umur penderita kanker payudara pasca kemoterapi sebagian berumur 45,50 tahun dan penderita berpendidikan SMA. Hasil penelitian ini sejalan dengan hasil penelitian (Pherson\&Steel, 2000) bahwa umur sanga penting sebagai faktor risiko kanker payudara. Kejadian kanker payudara meningkat cepat pada usia reproduktif dan setelah itu meningkat pada laju yang lebih rendah. Wanita berumur lebih dari 30 tahun mempunyai kemungkinan yang lebih besar untuk terkena kanker payudara. Risiko ini akan terus meningkat sampai umur 50 tahun dan setelah menopause (Dupont \& Page, 2004).

Menurut Moons, dkk dan Dalkey dalam (Nofitri, 2009) mengatakan bahwa usia adalah salah satu faktor yang mempengaruhi kualitas hidup. Penelitian yang dilakukan oleh Wagner, Abbot, \& Lett dalam (Nofitri, 2009) menemukan adanya perbedaan yang terkait dengan usia dalam aspek-aspek kehidupan yang penting bagi individu. Berdasarkan penelitian yang dilakukan oleh Ryff dan Singer dalam (Nofitri, 2009), individu dewasa mengekspresikan kesejahteraan yang lebih tinggi pada usia dewasa madya. Penelitian yang dilakukan oleh Rugerri, dkk dalam (Nofitri, 2009) menemukan adanya kontribusi dari faktor usia tua terhadap kualitas hidup subjektif.

Sedangkan pendidikan menurut Moons, dkk dan Baxter dalam (Nofitri, 2009) mengatakan bahwa tingkat pendidikan adalah salah satu faktor yang dapat mempengaruhi kualitas hidup subjektif. Penelitian yang dilakukan oleh Wahl, dkk dalam (Nofitri, 2009) menemukan bahwa kualitas hidup akan meningkat seiring dengan lebih tingginya tingkat pendidikan yang didapatkan oleh individu. Penelitian yang dilakukan oleh Noghani, dkk dalam (Nofitri, 2009) menemukan adanya pengaruh positif dari pendidikan terhadap kualitas hidup subjektif namun tidak banyak.

\section{Dukungan Spiritual}

Hasil penelitian ini didapat bahwa sebagian besar pre intervensi penderita kanker payudara pasca kemoterapi memiliki dukungan spiritual yang tidak baik dan hampir seluruh post intervensi penderita kanker payudara pascakemo terapi memiliki dukungan spiritual yang baik. Spiritual adalah keyakinan dalam hubungannya dengan yang Yang Maha Kuasa dan Maha Pencipta. Menurut Burkhardt 
(1993) spiritualitas meliputi aspek-aspek: 1) Berhubungan dengan sesuatu yang tidak diketahui atau ketidakpastian dalam kehidupan, 2) Menemukan arti dan tujuan hidup, 3) Menyadari kemampuan untuk menggunakan sumber dan kekuatan dalam diri sendiri, 4) Mempunyai perasaan keterikatan dengan diri sendiri dan dengaan Tuhan Yang Maha Tinggi. Mempunyai kepercayaan atau keyakinan berarti mempercayai atau mempunyai komitmen terhadap sesuatu atau seseorang.

Menurut Nolan dan Crawford (1997) kebutuhan spiritual sekelompok orang meliputi keinginan kelompok tersebut untuk dapat memberikan kontribusi positif terhadap lingkungannya. Dalam kenyataannya, semua manusia memiliki dimensi spiritual, semua klien akan mengekspresikan dan memanifestasikan kebutuhan spiritual mereka kepada perawat. Karena kurangnya pemahaman tentang kebutuhan spiritual klien, seringkali perawat gagal dalam mengenali ekspresi kebutuhan spiritual klien, sehingga perawat gagal dalam memenuhi kebutuhan tersebut. Kesejahteraan spiritual, merupakan suatu kondisi yang ditandai adanya penerimaan hidup, kedamaian, keharmonisan, adanya kedekatan dengan Tuhan, diri sendiri, masyarakat, dan lingkungan sehingga menunjukkan adanya suatu kesatuan (Greer dan Mober, 1998). Dalam hierarki kebutuhan dasar manusia, kesejahteraan spiritual termasuk dalam tingkat kebutuhan aktualisasi diri.

\section{Kualitas Hidup}

Hasil penelitian ini didapat bahwa sebagian besar pre intervensi penderita kanker payudara pasca kemoterapi memiliki kualitas hidup pada kesehatan fisik dan pada kesehatan mental yang tidak baik, sebagian memiliki kualitas hidup pada dukungan sosial dan lingkungan yang tidak baik. Sebagian post intervensi penderita kanker payudara pasca kemoterapi memiliki kualitas hidup pada kesehatan fisik, kesehatan mental, dukungan sosial dan lingkungan yang baik.

Setiap individu memiliki kualitas hidup yang berbeda tergantung dari masing-masing individu dalam menyikapi permasalahan yang terjadi dalam dirinya. Jika menghadapi dengan positif maka akan baik pula kualitas hidupnya, tetapi lain halnya jika menghadapi dengan negatif maka akan buruk pula kualitas hidupnya. Kreitler \& Ben dalam Nofitri (2009) kualitas hidup diartikan sebagai persepsi individu mengenai keberfungsian mereka di dalam bidang kehidupan. Lebih spesifiknya adalah penilaian individu terhadap posisi mereka di dalam kehidupan, dalam konteks budaya dan system nilai dimana mereka hidup dalam kaitannya dengan tujuan individu, harapan, standar serta apa yang menjadi perhatian individu (Nofitri, 2009).

Menurut WHO dalam (Bangun 2008), kualitas hidup didefenisikan sebagai persepsi individu sebagai laki-laki atau wanita dalam hidup, ditinjau dari konteks budaya dan system nilai dimana mereka tinggal, dan berhubungan dengan standar hidup, harapan, kesenangan, dan perhatian mereka. Hal ini merupakan konsep tingkatan, terangkum secara kompleks mencakup kesehatan fisik, status psikologis, tingkat kebebasan, hubungan sosial dan hubungan kepada karakteristik lingkungan mereka.

Di dalam bidang kesehatan dan aktivitas pencegahan penyakit, kualitas hidup dijadikan sebagai aspek untuk menggambarkan kondisi kesehatan Wilson dkk dalam (Larasati, 2012). Adapun menurut Cohen \& Lazarus dalam (Larasati, 2012) kualitas hidup adalah tingkatan yang menggambarkan keunggulan seorang individu yang dapat dinilai dari kehidupan mereka. Kualitas hidup individu tersebut biasanya dapat dinilai dari kondisi fisiknya, psikologis, hubungan sosial dan lingkungannya WHOQOL Group dalam (Larasati, 2012).

Kualitas hidup ditetapkan secara berbeda dalam penelitian lain. Namun dalam penelitian ini kualitas hidup adalah tingkatan yang menggambarkan keunggulan kualitas hidup seorang individu yang dapat dinilai berdasarkan konsep WHOQOL Group dari kesehatan fisik, psikologis, hubungan sosial dan lingkungan.

\section{Pengaruh Kualitas hidup terhadap dukungan spiritual}

Hasil penelitian didapat bahwa ada perbedaan kualitas hidup sebelum dan sesudah 
dilakukan dukungan spiritual pada penderita kanker payudara pasca kemoterapi di Kabupaten Rejang lebong tahun 2014 dengan nilai $p=0,008$. Hasil penelitian ini sejalan dengan penelitian Pradana,dkk (2012) di RS Sanglah Bali menunjukan hubungan kualitas hidup dengan kebutuhan perawatan paliatif menunjukan bahwa terdapat hubungan yang signifikan antara kualitas hidup dengan kebutuhan perawatan paliatif pada pasien kanker di RSUP Sanglah Denpasar. Berdasarkan nilai koefisien korelasi (r) dapat disimpulkan tingkat hubungan antar variabel tersebut sangat kuat. Hal ini sejalan dengan hasil penelitian Skilbeck, et al (2002) yang meneliti tentang pengkajian terhadap kebutuhan perawatan paliatif pada pasien kanker nasopharyngeal. Hasil penelitian ini menemukan bahwa semakin rendah kualitas hidup, berhubungan dengan tingkat isolasi sosial yang tinggi dan distres emosional, yang juga berhubungan dengan rendahnya fungsi fisik dan adanya keti-dakmampuan, serta gejala-gejala fisik. Hal ini menyebabkan dibutuhkan perawatan kesehatan dan sosial yang lebih tinggi dimana perawatan paliatif diharapkan bisa menjadi pilihan terbaik untuk memenuhi kebutuhan pasien kanker.

Berdasarkan teori, kualitas hidup berhubungan dengan gejala, fungsi, psikologis, sosial kesejahteraan, dan mungkin tingkat terendah untuk pemenuhan kebutuhan. Kualitas hidup sangat terkait dengan normalitas, termasuk fungsi normal atau kebutuhan minimal manusia yang harus terpenuhi. Menilai kualitas hidup dengan jelas dan menyeluruh membantu menentukan kapan harus memberikan perawatan paliatif (World Health Organization Quality of Life Group, 2010).

Sama halnya dengan hasil penelitian Khavari dalam Hisbullah (2007) menyatakan, kualitas tingkat kecerdasan spiritual seseorang dapat meningkat atau menurun. Kesadaran pribadi untuk mengasah secara aktif dalam kehidupan sehari-hari adalah faktor yang utama. Tiga hal yang membuat kualitas kecerdasan spiritual seseorang meningkat yaitu : selalu berkomunikasi dan berhubungan secara spiritual dengan Tuhan, mengem- bangkan sikap sosial yang menekankan segi kebersamaan dan kesejahteraan sosial, menanamkan kesadaran diri tentang etika sosial dan menerapkannya dalam perilaku. Kualitas kecerdasan spiritual akan meningkat apabila mengembangkan ketiganya dengan intensitas yang tinggi.

Didukung dengan penlitian Hendarnejad et al., (2009) dalam penelitian mengenai kualitas hidup penderita kanker pasca kemoterapi pada 200 pasien kanker, dimana diperoleh sebagian besar pasien tingkat kualitas hidupnya sedang. Berdasarkan teori, penurunan kualitas hidup pada penderita kanker dipengaruhi oleh faktor yang beranekaragam, seperti gejala, jenis perawatan yang diperoleh pasien, status penampilan pasien, depresi, dan keyakinan spiritual (Kreitler et al, 2007).

Menurut Khavari dalam Hisbullah (2007) juga menyatakan tingkat kecerdasan spiritual seseorang dapat meningkat atau menurun. Salah satu faktor yang mempengaruhi tingkat kecerdasan spiritual seseorang adalah selalu berkomunikasi dan berhubungan secara spiritual dengan Tuhan.

\section{KESIMPULAN}

Hasil penelitian dan pembahasan yang telah dikemukakan sebelumnya dapat diambil kesimpulan sebagai berikut : Sebagian umur 45,50 penderita kanker payudara pasca kemoterapi dan sebagian penderita berpendidikan SMA. Sebagian besar responden pre intervensi memiliki dukungan spiritual yang tidak baik. Hampir seluruh post intervensi dukungan spiritual penderita kanker payudara pasca kemoterapi baik.

Sebagian besar pre intervensi memiliki kualitas hidup pada kesehatan fisik dan mental yang tidak baik, sebagian memiliki kualitas hidup pada dukungan sosial dan lingkungan yang tidak baik. Sebagian post intervensi penderita kanker payudara pasca kemoterapi memiliki kualitas hidup pada kesehatan fisik, mental dukungan sosial dan lingkungan yang baik.

Diharapkan menyadari pentingnya deteksi dini kanker payudara dan lebih meningkatkan pengetahuan mengenai kanker. 
Masyarakat hendaknya aktif mengikuti penyuluhan kesehatan di lingkungannya atau puskesmas setempat atau pihak masyarakat bekerjasama dengan dinas kesehatan seperti

\section{DAFTAR RUJUKAN}

Taylor, S.E. (2003). Health Psychology. New York: McGraw-Hill.

Larasati. 2012. Kualitas Hidup Pada Wanita yang Sudah Memasuki Masa Menopouse. Skripsi Universitas Gunadarma.

World Health Organization. (1997). WHOQOL: Measuring Quality of Life.

Burton C.R, et al. 2010. The Palliative Care Needs of Cancer Patiens: a Prospective Study of Hospital Admissions, (online), (http://ageing. oxfordjournals.org/content/39/5/555.full, diakses 10 Agustus 2014).

Fayers et al. 2001. The EORTC QLQ-C30 scoring manual. 3rd ed. Brussels: European Organisation for Research and Treatment of Cancer, (online), (http://www.eortc.be/home/qol/files/SCManualQ LQ-C30.pdf, diakses 09Agustus2014).

Heydarnejad et al. 2009. Factors Affecting Quality of Life in Cancer Patients Undergoing Chemotherapy, (online), (http://www.ncbi.nlm.nih.gov /pmc/articles/PMC3158510/pdf/AFHS11020266.pdf, diakses 09 Agustus 2014).

Indrati, R. 2005. Faktor-faktor Risiko yang Berpengaruh Terhadap Kejadian Kanker Payudara Wanita, (online), (http://eprints.undip.ac.id /14998/1/2005E4D002071.pdf, diakses 09 Agustus 2014).

Kartawiguna, E. 2002. Faktor-faktor yang Berperan pada Karsinogenesis, (online), (http://www.univmed.org/wpcontent/uploads/20 11/02/Vol.20_no.1_3.pdf, diakses 10 Agustus 2014).

Kementrian Kesehatan Republik Indonesia (Menkes RI). 2007. Kebijakan Perawatan Paliatif, (online), (http://spiritia.or.id/Dok/skmenkes 812707.pdf, diakses 10 Agustus 2014).

Kreitler et al. 2007. Stress, Self-efficacy and Quality of Life in Cancer Patients, (online), (http://onlinelibrary.wiley.com/doi/10.1002/pon. 1063/pdf, diakses 17 Februari 2012).

Manuaba, T.W. 2008. Masalah Penanganan Kanker di Indonesia. Orasi Ilmiah. Pidato Pengukuhan Jabatan Guru Besar Tetap dalam Bidang Ilmu Bedah Fakultas Kedokteran Universitas Udayana. puskesmas untuk mengadakan kegiatan penyuluhan kesehatan mengenai penyakit kanker payudara.

Nuhonni, S. A. 2010. Kembang Rampai Perawatan Paliatif. Fakultas Kedokteran Universitas Indonesia: Jakarta.

Profil Kesehatan Indonesia. 2008. Profil Kesehatan Indonesia 2008, (online), (http://www.depkes.go.id/downloads/publikasi/P rofil\%20Kesehatan\%20Indonesia\%202008.pdf, diakses 15 Juni 2012).

Richardson et al. 2005. Patient's Needs Assesment Tool in Cancer Care: Principles and Practice.(http://www.kcl.ac.uk/teares/nmvc/exter nal/docs/ar-patients-needs-assessment-final.pdf, diakses 8 Maret 2012).

Riskesdas .2007. Riset Kesehatan Dasar : Laporan Nasional 2007, (online), (http://www.litbang.depkes.go.id/bl_riskesdas20 07/, diakses 10 Juni 2012).

Rusli, DN. 2011. Gambaran Explanatory Style pada Individu dalam Menghadapi Penyakit Kanker, (online),

(http://repository.usu.ac.id/bitstream/1234567

89/25646/5/Chapter\%20I .pdf, diakses 17 Februari 2012).

Sihombing, M. dan Sirait, N. M. 2007. Angka Ketahanan Hidup Penderita Kanker Ovarium di RS Dr. Cipto Mangunkusumo Jakarta, (online), (http://mki.idionline.org/index.php?uPage=mki. mki_dl\&smod=mki\&sp=public \&key=MTc1LTI $\mathrm{z}$, diakses 20 Juni 2012)

Skilbeck, et al. 2002. Palliative Care in Nasopharyngeal Cancer: a Need Assessment, (online),

(http://pmj.sagepub.com/content/12/4/249.abstra ct, diakses 10 Juni 2012).

Waller et al. 2011. Development of a Palliative Care Needs Assessment Tool (PC-NAT) for Use by Multi-Disciplinary Health Professionals. Centre For Health Research \& Psycho-Oncology, (online), (http://www.newcastle.

World Health Organisation Quality of Life Group. 2010. Study protocol for the World Health Organisation project to develop a Quality of Life assessment instrument (WHOQOL). Qual Life Res. 1993. 